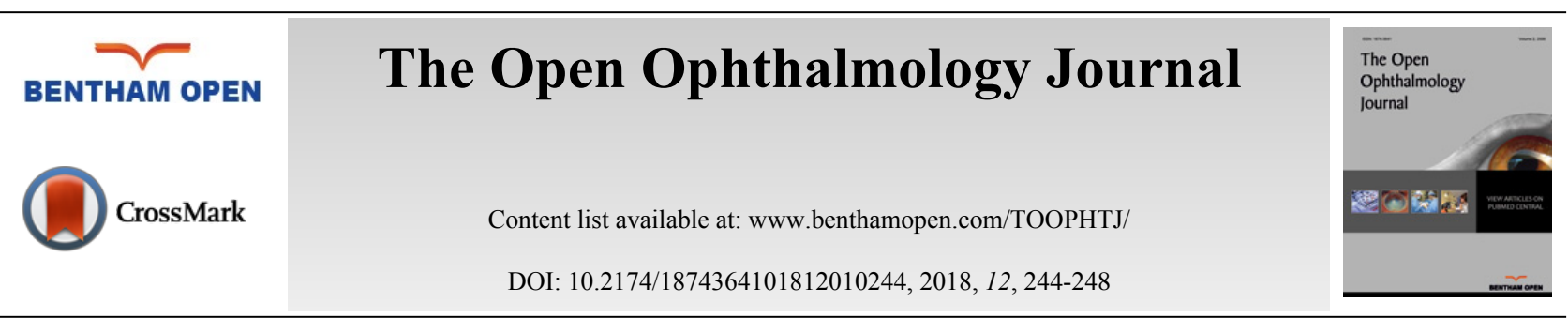

CASE REPORT

\title{
A New User-Friendly and Affordable Method in Descemet Stripping Endothelial Keratoplasty
}

\author{
Mohammad Soleimani ${ }^{*}$, Seyed Ali Tabatabaei and Reza Mirshahi \\ Eye Research center, Farabi Eye Hospital, Tehran University of Medical Sciences, Tehran, Iran
}

Received: April 7, 2018

Revised: June 21, 2018

Accepted: July 6, 2018

Abstract:

Aims:

To describe a new technique in Descemet Stripping Automated Endothelial Keratoplasty (DSAEK).

\section{Materials and Methods:}

In this technique, we use easily available materials (mainly a Nelaton tube) to make an injector for loading DSAEK lenticule and also easily pulling it (using a gauge 23 needle) into the eye. In this paper, we report outcomes of this technique in four cases.

\section{Results:}

Using these available instruments could easily lead to a clear postoperative cornea. Mean Endothelial Cell Density (ECD) loss at sixth postoperative month was $26 \%$.

\section{Conclusion:}

We proposed a novel effective user-friendly and affordable technique to perform DSAEK.

Keywords: DSAEK, Lenticule, Technique, Endothelial keratoplasty, ECD, PBK.

\section{BACKGROUND}

Descemet Stripping and Automated Endothelial Keratoplasty (DSAEK) is a selective lamellar corneal graft to replace the impaired endothelium layer [1]. There are numerous indications for performing DSAEK such as Fuchs endothelial dystrophy, Pseudophakic Bullous Keratopathy (PBK) and Iridocorneal Endothelial (ICE) syndrome eliminating the unwanted complications of Penetrating Keratoplasty (PKP) in these circumstances [2].

DSAEK involves dissection of donor's stroma via a microkeratome and inserting the folded posterior lenticule into the patient's Anterior Chamber (AC) after proper descemet - stripping [3 - 7]. Following the spreading and popularity of the DSAEK technique, new perspectives of potential complications were revealed including the endothelial trauma to the donor tissue resulting from the manipulation of the lenticule during insertion [7].

In the present study, we aim to describe an inexpensive modification to simplify lenticule delivery and minimize iatrogenic injury in a series of patients.

\section{CASE PRESENTATION (CASE SERIES)}

Herein, we report four consecutive cases of bullous keratopathy undergoing DSAEK procedure Table 1. Cases 1-3

* Address correspondence to this author at the Eye Research center, Farabi Eye Hospital, Tehran University of Medical Sciences, Tehran, Iran, E-mail: soleimani_md@yahoo.com 
underwent DSAEK in pseudophakic bullous keratopathy. A combined artisan Intraocular Lens (IOL) implantation and DSAEK was performed for case 4 because of Aphakic Bullous Keratopathy (ABK). Actually, that patient experienced a staphylococcal keratitis in the background of ABK. After administration of fortified cefazolin, his vision was counting fingers at 1 meter at the time of scar formation. DSAEK procedure was done two months later.

\section{INVESTIGATIONS}

Preoperative, first and sixth-month central Endothelial Cell Densities (ECDs) were measured using a non-contact specular microscope (TOPCON SP-2000P, Topcon, Tokyo, Japan).

\section{TREATMENT}

After marking superficial cornea with an 8-mm trephination, the endothelial layer is stained via trypan blue through a temporal corneal incision. Afterward, a $360^{\circ}$ descemetorhexis is fashioned along the trephination mark. Upon preparing the DSAEK lenticule, it is placed unfolded within a Nelaton catheter, cut using a Westcott scissor. It is preferred to create a beveled edge at the tip of the catheter to facilitate the introduction of lenticule into the AC Fig. (1a). In the following steps, an AC maintainer is fixed from a vertical corneal incision to provide a formed AC during donor's tissue delivery. The perpendicular intrastromal channel for the inflow, prevent disturbance of the lenticule by the tip of the instrument. Later, a clear corneal incision is made at nasal side opposite to the $5 \mathrm{~mm}$ incision. The beveled tip of the catheter is inserted in the AC through the temporal incision and by means of a 23-gauge needle from the opposite nasal port; the lenticule is pulled in to the AC Figs. (1b and 1c). Fig. (1d) presents a schematic view of pulling the lenticule into the eye.Finally, an air bubble is injected to the AC to maintain the lenticule position and the temporal incision is closed by 10-0 nylon sutures.

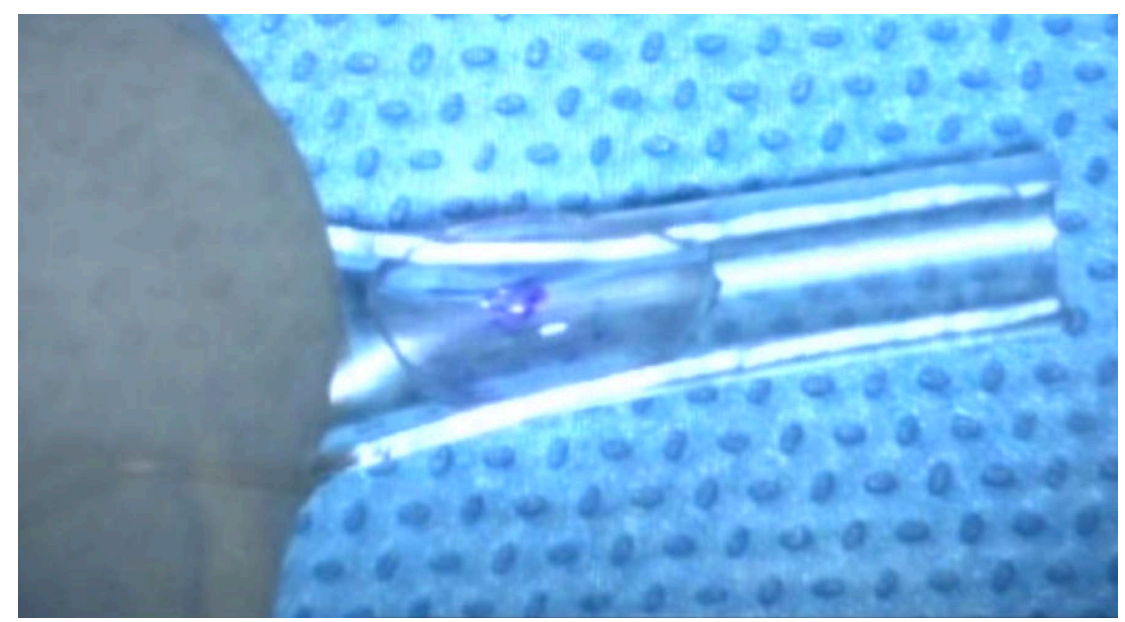

Fig. (1a). The injector was made of nelaton tube, the lenticule was loaded in the injector.

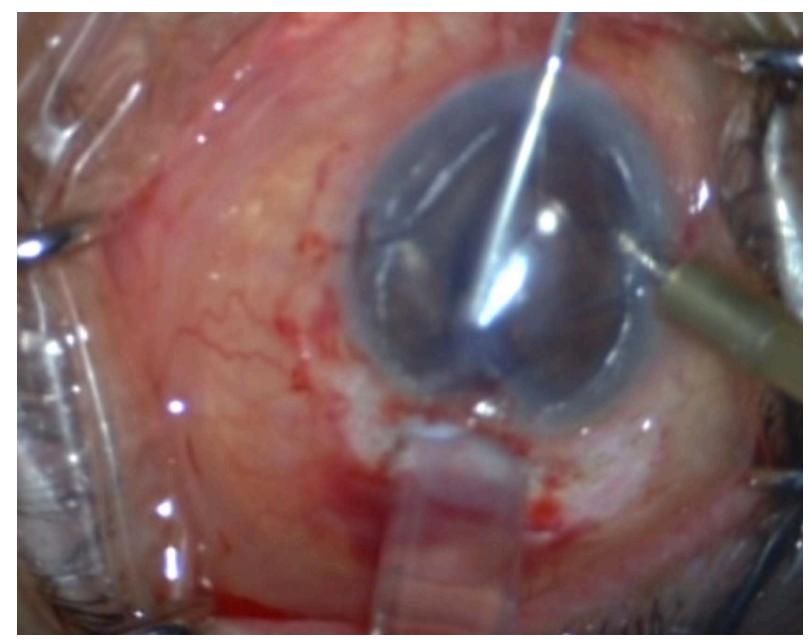

Fig. (1b). Pulling the lenticule using a gauge 23 needle. 


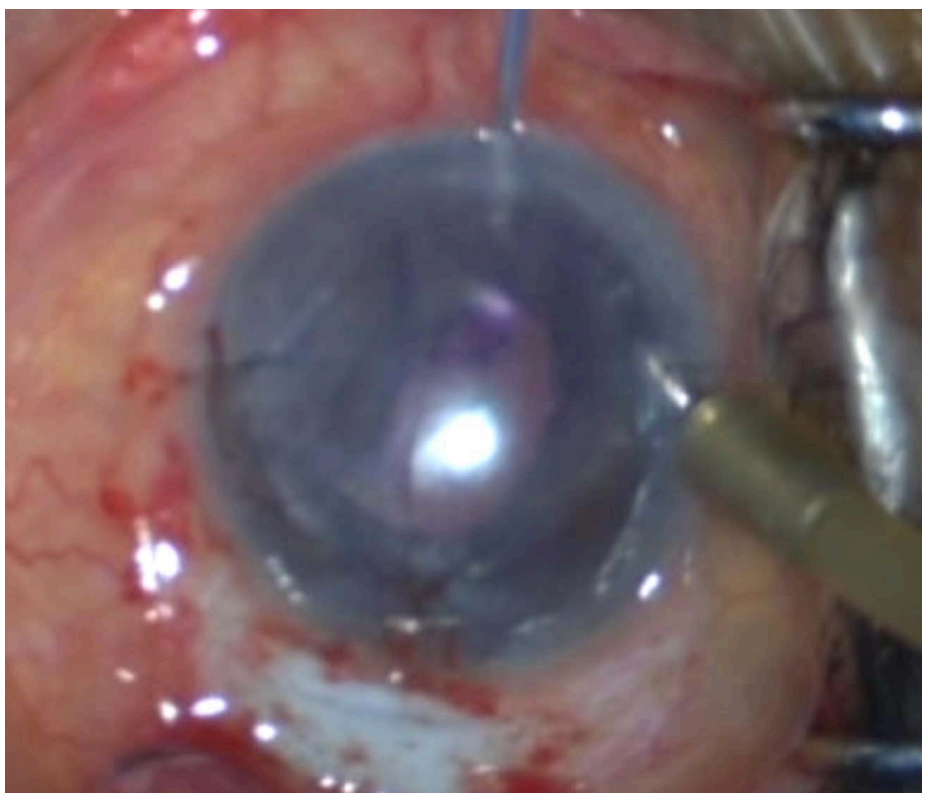

Fig. (1c). Pulling the lenticule using a gauge 23 needle.

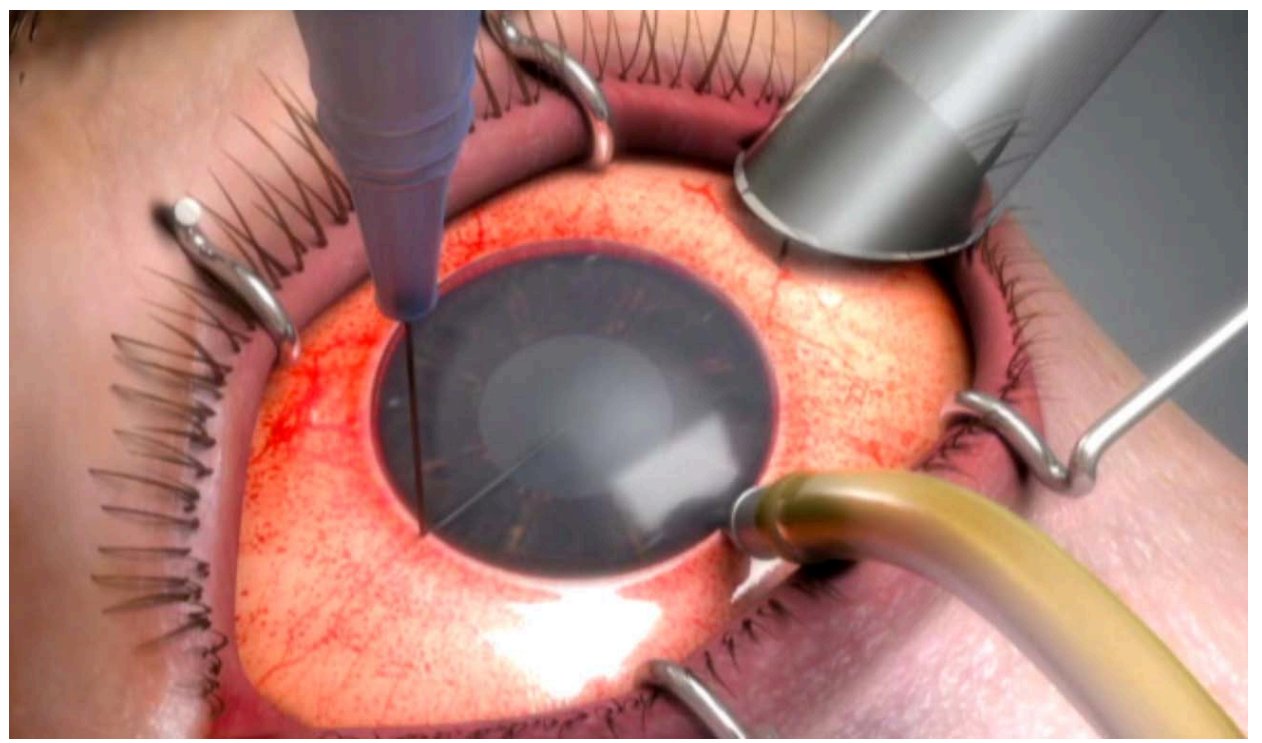

Fig. (1d). A schematic view of pulling the lenticule into the eye.

Attached video file (Video 1) completely explains this surgical technique.

\section{OUTCOMES AND FOLLOW-UP}

All grafts remain clear after six months. Table 1 shows ECD at different follow-ups, as the table shows mean ECD loss after six months was $26 \%$. We documented an ECD loss of $30 \%$ at sixth month in case 4 that underwent combined artisan IOL implantation and DSAEK, however, the cornea was clear with a best corrected visual acuity of 20/30.

Table 1. Pre-operative Endothelial Cell Density in the Donor and First and Six Month Values. ECD: Endothelial Cell Density (n/mm2).

\begin{tabular}{|c|c|c|c|c|}
\hline Patient & Preoperative ECD & First post-operative month ECD & Sixth post-operative month ECD & Decrease in ECD \\
\hline 1 & 2834 & 2022 & 2102 & $26 \%$ \\
\hline 2 & 3345 & 2745 & 2704 & $19 \%$ \\
\hline 3 & 2920 & 2253 & 2145 & $27 \%$ \\
\hline 4 & 3053 & 2083 & 2025 & $30 \%$ \\
\hline
\end{tabular}




\section{DISCUSSION}

In the current study, we introduced a new modification to DSAEK procedure using a device for lenticule delivery which is easily prepared intra-operatively. We believe that using this new technique, the iatrogenic trauma by the forceps during tissue grasping or during taco technique, could be reduced.

Ide et al. investigated in vitro damage of the forceps on donor endothelial layer. By means of vital dye, two parallel thick lines of devitalized cells matching the arms of forceps with other scattered areas of injury were identified in those models. Albeit, the crushing damage in the surgical setting can be substantially severe [7].

In 2007, Bradley and McCartney introduced a new technique for lenticule delivery using a double armed 10-0 Prolene suture which was applied on the apex of the donor's tissue. It was claimed that with suture-dragging, the lenticule positioning is simplified [8]. However, it is debated that further graft damage may ensue including the cheesewiring of the sutures during dragging and subsequently the need for manipulation by the forceps. In addition, it seems that the surgery is prolonged by suture-drag technique [9].

The pull-through technique discussed by Aralikatti et al. or using Busin glide is somehow similar to ours. They used a forcep for the insertion of graft tissue from a glide [9]. Our modification differs regarding the usage of widely available instruments in operation rooms and considering the fact that the small tip of 23-gauge needle is potentially the only surface that touches the lenticule. The decrease in ECD after six months was $26 \%$ in our proposed technique that was similar to Busin glide .

\section{CONCLUSION}

In conclusion, we postulate a new easy and affordable method to load and introduce the DSAEK lenticule into the AC. We need more studies to see if iatrogenic injury would be significantly mitigated resulting in better outcomes and longer graft survival.

Take Home Message:

1. DSAEK is a good technique for rehabilitating edematous cornea. Pull-through technique could decrease the risk of iatrogenic trauma to the lenticule.

2. We propose a new easy and affordable technique to load and introduce the DSAEK lenticule into the AC.

\section{ETHICS APPROVAL AND CONSENT TO PARTICIPATE}

The study protocol was approved by the local Ethical committee of Farabi Eye Hospital.

\section{HUMAN AND ANIMAL RIGHTS}

No Animals were used in this research. All human research procedures followed were in accordance with the ethical standards of the committee responsible for human experimentation (institutional and national), and with the Helsinki Declaration of 1975, as revised in 2013.

\section{CONSENT FOR PUBLICATION}

All participants provided written informed consent before any study procedure or examination was performed.

\section{CONFLICT OF INTEREST}

The authors declare no conflict of interest, financial or otherwise.

\section{ACKNOWLEDGEMENTS}

Declared none.

\section{SUPPLEMENTARY MATERIAL}

Supplementary material is available on the publishers Website along with the published article. 


\section{REFERENCES}

[1] Koenig SB, Covert DJ, Dupps WJ Jr, Meisler DM. Visual acuity, refractive error, and endothelial cell density six months after Descemet Stripping and Automated Endothelial Keratoplasty (DSAEK). Cornea 2007; 26(6): 670-4.

[http://dx.doi.org/10.1097/ICO.0b013e3180544902] [PMID: 17592314]

[2] Correll M, Stormly Hansen M, Hovlykke M, Hjortdal J, Olsen Julian H. Graft functionality after DSAEK surgeries in Denmark from 2006 to 2009. Acta Ophthalmol 2016; 94.

[3] Gorovoy MS. Descemet-stripping automated endothelial keratoplasty. Cornea 2006; 25(8): 886-9. [http://dx.doi.org/10.1097/01.ico.0000214224.90743.01] [PMID: 17102661]

[4] Terry MA, Ousley PJ. Endothelial replacement without surface corneal incisions or sutures: Topography of the deep lamellar endothelial keratoplasty procedure. Cornea 2001; 20(1): 14-8.

[http://dx.doi.org/10.1097/00003226-200101000-00002] [PMID: 11188996]

[5] Terry MA, Ousley PJ. Deep lamellar endothelial keratoplasty in the first United States patients: Early clinical results. Cornea 2001; 20(3): 239-43.

[http://dx.doi.org/10.1097/00003226-200104000-00001] [PMID: 11322409]

[6] Melles GR, Wijdh RH, Nieuwendaal CP. A technique to excise the descemet membrane from a recipient cornea (descemetorhexis). Cornea 2004; 23(3): 286-8.

[http://dx.doi.org/10.1097/00003226-200404000-00011] [PMID: 15084862]

[7] Ide T, Yoo SH, Goldman JM, Perez V, O’Brien TP. Descemet-stripping automated endothelial keratoplasty: Effect of inserting forceps on DSAEK donor tissue viability by using an in vitro delivery model and vital dye assay. Cornea 2007; 26(9): $1079-81$.

[http://dx.doi.org/10.1097/ICO.0b013e318142bdde] [PMID: 17893538]

[8] Bradley JC, McCartney DL. Descemet's stripping automated endothelial keratoplasty in intraoperative floppy-iris syndrome: Suture-drag technique. J Cataract Refract Surg 2007; 33(7): 1149-50. [http://dx.doi.org/10.1016/j.jcrs.2007.03.043] [PMID: 17586368]

[9] Aralikatti A, Dean S, Busin M, Shah S. Pull-through technique for graft insertion in DSAEK. J Cataract Refract Surg 2008; 34(3): 341. [http://dx.doi.org/10.1016/j.jcrs.2007.10.038] [PMID: 18299041]

\section{(C) 2018 Soleimani et al.}

This is an open access article distributed under the terms of the Creative Commons Attribution 4.0 International Public License (CC-BY 4.0), a copy of which is available at: (https://creativecommons.org/licenses/by/4.0/legalcode). This license permits unrestricted use, distribution, and reproduction in any medium, provided the original author and source are credited. 